\title{
Studies of the purine analog associated modulation of human erythrocyte acid phosphatase activity
}

\author{
K. Hans Wurzinger, Joseph E. Novotny and Harvey W. Mohrenweiser \\ Department of Human Genetics, University of Michigan Medical School, Ann Arbor, MI 48109-0010, \\ USA
}

Keywords: acid phosphatase, methanol interaction, purine modulation

\begin{abstract}
Summary
The activity of the human erythrocyte acid phosphatase is modulated by a series of structural analogs of purine. The unsubstituted purine base does not affect the enzyme activity. Addition of a substituent at the number six position usually generates an analog which activates the enzyme while similar substitutions at the two position usually generate an inhibitor. Pyrimidines are generally ineffective as modulators while several modifications of the imidazole ring of the purine analogs do not abolish the modulator activity of the purine analog. The level of response to all active analogs is isozyme specific. Differences in apparent relative affinities among the modulators are noted. The modulators with a positive effect on enzyme activity, are effective in the presence of methanol which is more effective than $\mathrm{H}_{2} \mathrm{O}$ as a phosphate acceptor. These analogs act by enhancing the rate of transfer of phosphate to $\mathrm{H}_{2} \mathrm{O}$, while decreasing the rate of transfer to methanol. The results suggest that the purine analogs may act by altering the rate of hydrolysis of the phosphoenzyme intermediate by $\mathrm{H}_{2} \mathrm{O}$ or may change the rate-limiting step in the catalytic mechanism.
\end{abstract}

\section{Introduction}

Human erythrocyte acid phosphatase (ACP, EC 3.1.3.2) is a monomeric enzyme of approximately 12-14000 dalton molecular weight (1). Three common alleles $\mathrm{ACP}_{1} \mathrm{~A}, \mathrm{ACP}_{1}{ }^{\mathrm{B}}$ and $\mathrm{ACP}_{1}{ }^{\mathrm{C}}$ are observed in human populations. These isozymes differ in electrophoretic mobility, level of activity and thermostability (2-7). Another characteristic of the erythrocyte ACP isozymes is the modulation of enzymatic activity by a series of purine analogs $(5,6,8-10)$. The response is observed as either enhancement or inhibition of the rate of product formation. The direction of the modulation is a specific function of the purine analog; each analog is either an activator or an inhibitor irrespective of the isozyme being studied. In contrast, the relative extent of the modulation is a function of the iso- zyme structure with the order of response being ACP-C: ACP-A: ACP-B. The C isozyme may be either the least or most responsive but it will always be at the opposite extreme from the B isozyme with the $\mathrm{A}$ isozyme and the various heterozygote combinations exhibiting intermediate levels of response. A similar consistent ordering of response is observed in studies of the purine modulation of erythrocyte ACP from other species (11). Thus, the absolute level of modulation is a function of the interaction of specific features of the purine analogs with binding sites on the ACP molecule. This interaction is sensitive to both the structure of the enzyme and the purine analog as reflected in the specificity of response noted among the allelic variants in the human population $(5,6,8,9)$ as well as among the isozymes from several species (11).

A low molecular weight ACP with many charac- 
teristics similar to the erythrocyte ACP has been identified in several tissues (12-18). The activity of the low molecular weight ACP from human liver (11) and placenta (19) and bovine liver (11) and brain (20) is also modulated by several purine analogs.

The catalytic mechanism of the ACP enzyme is proposed to involve a phosphoenzyme intermediate, with the rate-limiting step being transfer of the phosphate from the enzyme to an acceptor (21, 22 ). This would explain the rate enhancement observed when, in addition to $\mathrm{H}_{2} \mathrm{O}$, alcohols which are better acceptors than $\mathrm{H}_{2} \mathrm{O}$, are present as the acceptor in the assay $(5,7,20)$. The mechanism for the purine modulation, which exhibits uncompetitive kinetics $(8,20,21)$, is unclear although the data are consistent with facilitation of removal of the phosphate group from the enzyme (20). The mechanism does not involve either transphosphorylation to modulator or covalent binding of modulator to the enzyme (20).

This paper will report on some additional structural features of the purine analogs required for modulation of the activity of the human erythrocyte acid phosphatase. The interaction between pairs of modulators as well as modulators and alcohol will also be reported.

\section{Materials and methods}

Blood samples were collected, washed and stored as described by Fielek and Mohrenweiser (23). Hemolysates for electrophoresis were prepared as decribed by Mohrenweiser and Novotny (6). Vertical starch gel electrophoresis was utilized to confirm the ACP phenotypes (24). Hemolysates for activity studies were prepared and dialyzed as described by Yoshihara and Mohrenweiser (5).

ACP activity, with p-nitrophenyl phosphate (p-NPP) as substrate, was assayed as described by Mohrenweiser and Novotny (6) except that the buffer was $0.1 \mathrm{M}$ sodium acetate, adjusted to $\mathrm{pH} 5.5$ with $\mathrm{HCl}$ and the substrate concentration was $10 \mathrm{mM}$. The incubation time was $10 \mathrm{~min}$ at $37^{\circ} \mathrm{C}$. The extent of transphosphorylation to methanol was estimated by measuring p-nitrophenoxide $(\mathrm{p}-\mathrm{NP})$ and phosphate $(\mathrm{Pi})$ from the same reaction tube and the methylphosphate was calculated as the difference as done by Tanizaki et al. (20). The phos- phate assay used was that of Lanzetta et al. (25). All assays were done in duplicate and samples from two individuals of each phenotype were used. The variation among individuals and/or replicates was less than $5 \%$. The rate of product formation was linear with time for all assay conditions employed.

All purine and pyrimidine analogs, as well as p-nitrophenyl phosphate, were obtained from Sigma Chem. Co. and used without further purification.

\section{Results}

\section{Structural specificity for modulation}

The data on the effect of various purine analogs on ACP activity are summarized in Table 1 . As in most previous studies, the B-type isozyme (the most common variant in human populations) was used for initial studies. Enzyme from heterozygous $\mathrm{ACP}_{1} \mathrm{AC}$ type individuals was also used for further studies, which confirmed previous observations that the extent but not the direction of modulation is isozyme specific. The unsubstituted purine base is ineffective as a modulator of human erythrocyte ACP activity. Addition of a substituent at the number 6-position of the purine base, with the exception of a chlorine atom, generates a series of activators which enhance the rate of product formation by up to 4 -fold. Isozyme specificity is observed, with the BB phenotype being most responsive to the addition of the $-\mathrm{OH}$ and $-\mathrm{SH}$ adducts while the two amino derivatives, $-\mathrm{NH}_{2}$ and $-\mathrm{N}$ $\left(\mathrm{CH}_{3}\right)_{2}$ are the better enhancers of the activity of the $\mathrm{AC}$ phenotype. Replacement of the $-\mathrm{SH}$ by the larger $-\mathrm{S}-\mathrm{CH}_{2}-\mathrm{CH}_{3}$ adduct reverses the genotype specificity and the level of enhancement by the analog with the larger adduct is reduced.

Addition of an amino group at the 2-position instead of the 6-position of the base generates an inhibitor instead of an activator. The addition of the -OH or -SH group to the 2-position of the purine base is without significant effect, relative to the unsubstituted base but this ineffectiveness is in contrast to the positive modulation observed when these groups were at the 6-position.

The 2,6-disubstituted purine bases are either activators or inhibitors, depending upon the adducts. With the exception of the $6-\mathrm{NH}_{2}$ derivative, all of 
Table 1. Modulation of ACP activity by a series of purine analogs.

\begin{tabular}{|c|c|c|c|c|c|}
\hline \multirow[t]{2}{*}{ Compound } & \multicolumn{3}{|c|}{ Structure } & \multicolumn{2}{|c|}{ Activity } \\
\hline & $2^{\mathrm{a}}$ & 6 & Ring $b$ & $\mathrm{BB}$ & $\mathrm{AC}$ \\
\hline purine & $\mathrm{X}$ & $\mathrm{X}$ & PU & 93 & 100 \\
\hline 6-hydroxy purine (hypoxanthine) & $X$ & $\mathrm{OH}$ & PU & 203 & 144 \\
\hline 6-mercapto purine & $\mathrm{X}$ & SH & PU & 292 & 170 \\
\hline 6-amino purine (adenine) & $\mathrm{X}$ & NH & PU & 131 & 225 \\
\hline 6-chloro purine & $\mathrm{X}$ & $\mathrm{Cl}$ & $\mathrm{PU}$ & 81 & 83 \\
\hline 6-dimethylamino purine & $X$ & $\mathrm{~N}-\left(\mathrm{CH}_{3}\right)_{2}$ & $\mathrm{PU}$ & 387 & 589 \\
\hline 6-ethylmercapto purine & $\mathbf{X}$ & $\mathrm{S}-\mathrm{CH}_{2} \mathrm{CH}_{3}$ & $\mathrm{PU}$ & 143 & 211 \\
\hline 2-hydroxy purine & $\mathrm{OH}$ & $\mathrm{X}$ & PU & 100 & 118 \\
\hline 2-mercapto purine & $\mathrm{SH}$ & $x$ & $\mathrm{PU}$ & 78 & 92 \\
\hline 2-amino purine & $\mathrm{NH}$ & $\mathrm{x}$ & $\mathrm{PU}$ & 47 & 60 \\
\hline 2-hydroxy-6-thio purine & $\mathrm{OH}$ & $\mathrm{SH}$ & PU & 190 & 145 \\
\hline 2-hydroxy-6-amino purine (isoquanine) & $\mathrm{OH}$ & NH & PU & 77 & 70 \\
\hline 2-hydroxy-6-methyl purine & $\mathrm{OH}$ & $\mathrm{CH}$ & PU & 112 & 143 \\
\hline 2-thio-6-hydroxy purine & $\mathrm{SH}$ & $\mathrm{OH}$ & PU & 90 & 86 \\
\hline 2,6-dihydroxy purine (xanthine) & $\mathrm{OH}$ & $\mathrm{OH}$ & PU & 116 & 121 \\
\hline 2-amino-6-hydroxy purine (guanine) & NH & $\mathrm{OH}$ & PU & 62 & 68 \\
\hline 2-amino-6-mercapto purine & $\mathrm{NH}$ & $\mathrm{SH}$ & PU & 90 & 78 \\
\hline 2,6-diamino purine & NH & $\mathrm{NH}$ & $\mathrm{PU}$ & 25 & 31 \\
\hline uric acid & $\mathrm{OH}$ & $\mathrm{OH}$ & PU & 85 & 70 \\
\hline adenosine & $\mathrm{X}$ & NH & PU-R & 97 & 102 \\
\hline inosine & $\mathrm{X}$ & $\mathrm{OH}$ & PU-R & 164 & 233 \\
\hline guanosine & $\mathrm{NH}$ & $\mathrm{OH}$ & PU-R & 208 & 325 \\
\hline 6-mercaptoguanosine & $\mathrm{NH}$ & $\mathrm{SH}$ & PU-R & 178 & 200 \\
\hline 6-chloroguanosine & NH & $\mathrm{Cl}$ & PU-R & 99 & 99 \\
\hline 7-methylguanosine & NH & $\mathrm{OH}$ & PU-R & 85 & 83 \\
\hline 1-methylguanosine & $\mathrm{NH}$ & $\mathrm{OH}$ & PU-R & 99 & 101 \\
\hline allopurinol & $\mathrm{X}$ & $\mathrm{OH}$ & ALP & 215 & 171 \\
\hline hydroxypteridine & $\mathrm{X}$ & $\mathrm{OH}$ & $\mathrm{PT}$ & 100 & 100 \\
\hline lumazine & $\mathrm{OH}$ & $\mathrm{OH}$ & $\mathrm{PT}$ & 96 & 107 \\
\hline folic acid & $\mathrm{NH}$ & $\mathrm{OH}$ & $\mathrm{PT}$ & 46 & 25 \\
\hline xanthopterin & $\mathrm{OH}$ & $\mathrm{NH}$ & PT & 76 & 65 \\
\hline
\end{tabular}

All of the compounds were present at a concentration of $5.0 \mathrm{mM}$ except for guanine, isoguanine, and folic acid at $1.0 \mathrm{mM}$ and xanthine, dimethylamino purine and uric acid at $2.5 \mathrm{mM}$. Activity is expressed as percent of activity in the absence of purine analog. The responses of both the $\mathrm{BB}$ and $\mathrm{AC}$ isozymes were studied.

a Substituent at the 2- and/ or 6-position of the purine. $\mathrm{X}$ indicates no adduct present.

b The basic ring structures are as follows: PU - purine; PUR - purine riboside; ALP - pyrazolopyrimidine; PT - pteridine.

the $2-\mathrm{OH}$ analogs are activators, although the extent of activation is not of the magnitude observed with the 6 substituted analogs. The interchange of the - $\mathrm{OH}$ and $-\mathrm{SH}$ groups, from the 2-OH, 6-SH to the 2-SH, 6-OH configuration, changes the purine analog from a good activator to a relatively inactive compound. An $-\mathrm{NH}_{2}$ group at the 2-position, in conjunction with any substituent at the 6-position, results in a negative modulator, with the 2,6 -diamino analog being a potent inhibitor. Additions at other positions, in addition to the 2- and 6-positions, usually results in a relatively ineffective modulator, with only uric acid exhibiting significant (inhibitory) activity. Theophylline, theobromine and caffeine were all without significant modulator activity.

The addition of the ribose moiety to the purine base has a significant effect on the functionality of the various analogs. The 6- $\mathrm{NH}_{2}$-substituted purine (adenine) is a good activitor of ACP activity, while 
the 6- $\mathrm{NH}_{2}$-substituted nucleoside (adenosine) is ineffective as a modulator. Both of the 6-OH-substituted analogs are activators but the $\mathrm{BB}$ isozyme is most responsive to the purine base (hypoxanthine) while the $\mathrm{AC}$ isozyme is activated to a greater extent by the nucleoside (inosine). The 2- $\mathrm{NH}_{2}, 6-\mathrm{OH}$ substituted purine (guanine) is an inhibitor. However, the corresponding nucleoside (guanosine) activates the $\mathrm{BB}$ and $\mathrm{AC}$ isoenzymes 2- and 3-fold respectively. The 6-SH derivative of guanosine is less effective than guanosine as an activator and substitution of a chloro group for the $-\mathrm{OH}$ at the 6-position generates an analog which is inactive. Also, addition of a methyl group at either the number 1 or 7 nitrogen of guanosine results in an inactive analog. Guanosine and mercaptoguanosine were unique in being the only 2-amino-substituted compounds which were positive modulators of ACP activity.

It seems clear that additions to the pyrimidinyl ring have a key role in the modulation of ACP activity by purine analogs. It is equally clear that the functional mechanism must require a 'purinelike' ring structure in that a series of pyrimidine analogs are, at most, minimally effective in modulating ACP activity. The pyrimidines, cytosine, 2-aminopyrimidine, 2-hydroxypyrimidine 2-thio, 4-amino-6-hydroxypyrimidine, 2-mercaptopyrimidine and alloxan, have no significant modulating effect on ACP activity. Only the 2-hydroxy-substituted compound, isocytosine, has any modulating effect being a weak inhibitor of both isozymes ( 77 and $63 \%$ of control for $\mathrm{BB}$ and $\mathrm{AC}$ respectively).

The replacement of the imidazole ring with a pyrazole ring seems to have minimal effect, as allopurinol has a modulating effect which is very similar to that observed for hypoxanthine. Substitution of a pyrazine ring, for the imidazole ring also is without significant effect for three analogs, although two are inhibitors and the third is inactive. Lumazine (inactive), folic acid (inhibitor), and xanthopterin (inhibitor) have modulator activities quite similar to the appropriate purine a nalogs. The exception is the activator, hypoxanthine as the pyrazine analog, 4-hydroxyteridine is ineffective as a modulator. Addition of a methyl group at the 7nitrogen of the imidazole ring (7-methyl guanosine) results in the loss of activation capability while addition of a hydroxyl group at carbon 8 (uric acid) creates an analog which is an inhibitor rather than a weak activator (xanthine).

\section{Analog combinations}

The modulation of ACP activity by combinations of analogs was investigated in several series of experiments. In the first experiment, pairs of modulators were mixed in ratios to maintain a constant combined concentration of modulators. Two types of results were observed. The first was that observed with the combination of the activator, 6a minopurine (adenine) and the inhibitor, 2-aminopurine, where the activity observed in the presence of both modulators was simply the average of the two modulators alone. A similar response was seen when the two activators - guanosine and 6-aminopurine, were used together. The response is that expected for 2 modulators competing equally for the same site.

The second type of response was that observed with combinations which included folic acid. Equal molar concentrations of folic acid and either the activator, guanosine or the inhibitor, 2,6-diaminopurine yielded the same response as observed with folic acid alone. In fact, folic acid at $0.25 \mathrm{mM}$ concentration completely inhibited the activating capacity of $1.0 \mathrm{mM}$ guanosine. In contrast, various ratios of guanosine and 2,6-diaminopurine produced a level of modulation consistent with a simple additive respone.

These mixing experiments indicated a differential or dominating effect of some modulators, thus the concentration dependence of the response to 5 different compounds was examined. Due to the great differences in the levels of modulation produced by the different analogs, the data are plotted as a percent of the maximum modulation observed for each compound for each isozyme. Figure 1A clearly indicates that the purine analogs fall into two groups, which differ greatly in their effectiveness as activators of ACP activity. Dimethylaminopurine is maximally effective at approximately $2 \mathrm{mM}$ while guanosine and 6-mercaptopurine require more than $6 \mathrm{mM}$ effector for maximal activation. Both genotypes respond in a similar manner to these activators. The inhibitors, in contrast, showed a phenotype-specific effect (Fig. 1B). The shape of the curve is phenotype dependent; the inhibition of the $\mathrm{BB}$ isozyme is greater, at lower effector concentrations, for diaminopurine while the $\mathrm{CC}$ phenotype is more sensitive to folic acid inhibition. The differences in response are approximately 2 -fold at inhibitor concentrations of less than $1 \mathrm{mM}$. 

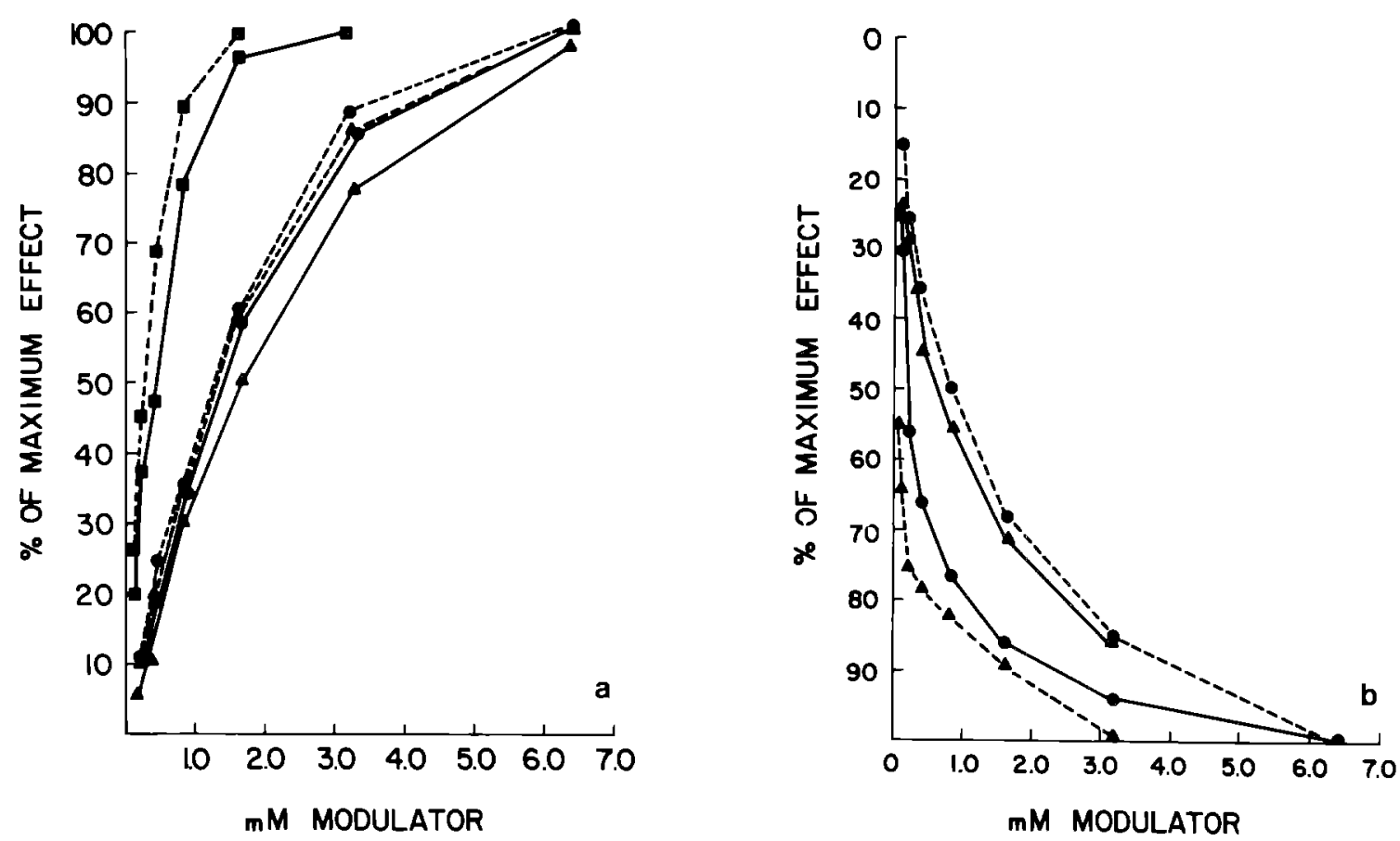

Fig. 1. Concentration dependence of modulation. Activity is expressed as percent of maximum response. (-) BB phenotype; (--) CC

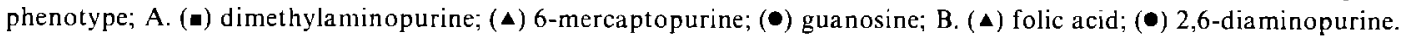

In an additional series of experiments, several inactive purine analogs were mixed with the activator, guanosine. The concentration of the inactive analogs were held constant at $1 \mathrm{mM}$ while the concentration of guanosine was varied from 0.25 to 1.0 $\mathrm{mM}$. Two types of results could be expected from this series. If the inactive analog binds to the enzyme molecule at the same site as the activator, it would reduce the binding of the activator and thereby reduce the modulation observed. If, on the other hand, the inactive analog does not bind to the enzyme, then no deviation from the level of modulation by guanosine alone would be expected. Both of these results were observed. 4-hydroxypteridine, and to a lesser degree 1-methylguanosine, clearly reduced $(15-25 \%)$ the activation observed with guanosine alone. Adenosine and 2-hydroxypyrimidine had no effect, i.e., they did not seem to bind to the enzyme. When 4-hydroxypteridine was mixed with guanosine so as to maintain a constant concentration of purine analogs, the resulting respose was again that expected for two modulators competing for the same site. This is further evidence that this inactive analog is competing for the modulator site on the enzyme but is unable to enhance (or inhibit) the rate of catalysis.

\section{Analog-methanol interaction}

The rate of product ( $p$-nitrophenoxide) formation is also enhanced by the addition of alcohol to the reaction mix, the enhancement being via a transphosphorylation mechanism (20). Thus, we examined the interaction of methanol plus a series of modulators.

The degree to which various modulators affect the rate of product ( $\mathrm{p}-\mathrm{NP}$ ) formation in the absence and presence of methanol is summarized in Table 2. Guanosine and 6-dimethylaminopurine enhance the rate of product formation, for both the BB and AC phenotypes, above that observed with methanol alone; 6-mercaptopurine shows the enhancement effect for the $\mathrm{BB}$, but not for the $\mathrm{AC}$ isozymes. Adenine and hypoxanthine show no enhancement and, in fact, they inhibit the rate of product formation, relative to the rate with methanol alone for the lesser responsive isozyme. This latter rate is above the rate observed when the assay is conducted with 
Table 2. Interaction of methanol and purine analogs in modulating ACP.

\begin{tabular}{lllll}
\hline Phenotype & \multicolumn{3}{l}{ Activity } & \\
\cline { 2 - 5 } & BB & & AC \\
\cline { 2 - 5 } & $\begin{array}{l}\text { without } \\
\text { meth- } \\
\text { anol }\end{array}$ & $\begin{array}{l}\text { meth- } \\
\text { anol }\end{array}$ & $\begin{array}{l}\text { without } \\
\text { meth- } \\
\text { anol }\end{array}$ & $\begin{array}{l}\text { meth- } \\
\text { anol }\end{array}$ \\
& \multicolumn{3}{l}{} & \\
\hline Control & 100 & 278 & 100 & 277 \\
6-dimethylaminopurine & 406 & 478 & 653 & 654 \\
6-mercaptopurine & 278 & 343 & 191 & 258 \\
Guanosine & 189 & 319 & 305 & 377 \\
Hypoxanthine & 153 & 279 & 130 & 247 \\
Adenine & 131 & 200 & 197 & 263 \\
2,6-diaminopurine & 29 & 61 & 38 & 97 \\
Folic acid (1,0 mM) & 50 & 130 & 33 & 70 \\
Folic acid (0.1 mM) & 67 & 150 & 47 & 95 \\
\hline
\end{tabular}

Methanol was present as $10 \%$ of the reaction volume while all purine analogs were present at a concentration of $2.5 \mathrm{mM}$ except for folic acid which was at $1.0 \mathrm{mM}$ and $0.1 \mathrm{mM}$. Assays were as described in 'Methods' and activity is expressed as percent of the activity in absence of either methanol or analog for each genotype. The responses of both the $\mathrm{BB}$ and $\mathrm{AC}$ isozymes were studied.

modulator but without methanol. The enhancement effect of guanosine, observed in the presence of methanol, is eliminated as the methanol concentration in the assay system is increased to $30 \%$ methanol.

The two inhibitors, folic acid and diaminopurine, reduce the rate of product formation to $25-50 \%$ of that observed with methanol alone. The rate of transfer of phosphate to $\mathrm{H}_{2} \mathrm{O}$ in the presence of either inhibitor is not altered by the addition of methanol. Thus, the relative effectiveness of the inhibitors is not significantly altered by the addition of $10 \%$ methanol.

In order to investigate the methanol enhancement effect further, the response of several additional isozymes of human ACP, to incubation with activator plus methanol, was examined (Table 3 ). Enhancement of the rate by guanosine in the presence of $10 \%$ methanol is observed for all genotypes with the greatest effect being shown by those genotypes which are most responsive to guanosine. The a nalog 6-mercaptopurine is a less effective activator and two different responses are observed when the reaction rate is measured in the presence of methanol. With the more responsive isozymes, $\mathrm{BB}$ and AA, 6-mercaptopurine enhances (20 and 10\% re-
Table 3. Effect of methanol on the modulating effect of guanosine and 6-mercaptopurine for five ACP phenotypes.

\begin{tabular}{llllll}
\hline Treatment & \multicolumn{7}{l}{ ACP phenotypes } \\
\cline { 2 - 6 } & BB & AA & BC & AC & CC \\
\hline Control & 100 & 100 & 100 & 100 & 100 \\
Methanol & 277 & 276 & 265 & 266 & 259 \\
Guanosine & 188 & 220 & 266 & 293 & 328 \\
Guanosine + methanol & 319 & 335 & 347 & 366 & 375 \\
6-mercaptopurine & 275 & 246 & 189 & 182 & 147 \\
6-mercaptopurine + & & & & & \\
$\quad$ methanol & 334 & 307 & 245 & 247 & 214 \\
\hline
\end{tabular}

Methanol was present as $10 \%$ of the reaction volume and purines at a concentration of $2.5 \mathrm{mM}$. Assays were conducted as described in 'Methods'. Activity is expressed as the percent of activity in the absence of modulator and methanol, for each isozyme.

spectively) the rate above that observed with methanol alone. The addition of the analog results in a reduction to only $80 \%$ of the rate for methanol alone for the least responsive isozyme (CC). The data suggest a threshold for responsiveness, with a modulator required to enhance the reaction rate, in the absence of methanol, some 1.8-2.0-fold before it elicits a positive response in the presence of $10 \%$ methanol.

\section{Product formation}

With reactions conducted in the presence of methanol and $\mathrm{H}_{2} \mathrm{O}$, the phosphate can be transferred to either acceptor (20). The effect of several modulators on the distribution of products is summarized in Table 4 . The addition of $10 \%$ methanol to the assay enhances the reaction rate some 2.5-2.8 times. The methylphosphate to phosphate ratio is approximately $2: 1$ for both phenotypes. The addition of any of the four analogs which enhance ACP activity results in an increased rate of phosphate transfer to $\mathrm{H}_{2} \mathrm{O}$ and a decrease in the rate of transfer to methanol when the reaction is conducted in the presence of both methanol and analog. The net effect on the total reaction rate is dependent upon the relative changes (which are in opposite directions) in each reaction. For example, the addition of dimethylaminopurine is associated with a $25-50 \%$ decrease in the amount of methylphosphate formed and a 3-5-fold increase in the transfer to $\mathrm{H}_{2} \mathrm{O}$. Guanosine addition is associated with only 
Table 4. Distribution of reaction products in the presence and absence of methanol for six modulators of ACP activity.

\begin{tabular}{|c|c|c|c|c|c|c|}
\hline & \multicolumn{6}{|c|}{ Distribution of products } \\
\hline & \multicolumn{3}{|c|}{$\mathrm{BB}$} & \multicolumn{3}{|c|}{$\mathrm{AC}$} \\
\hline & $\mathrm{P}-\mathrm{NPa}$ & $P_{i}$ & Me-P & $\mathrm{P}-\mathrm{NP}$ & $\mathrm{P}_{\mathrm{i}}$ & Me-P \\
\hline 1. Control & $36^{\mathrm{a}}$ & 36 & - & 38 & 38 & - \\
\hline 2. Methanol & 102 & 33 & 69 & 101 & 34 & 65 \\
\hline 3. 6-dimethyla minopurine & 126 & 126 & - & 208 & 204 & - \\
\hline 4. 6-DMAP plus methanol & 153 & 104 & 49 & $2 ! 1$ & 182 & 29 \\
\hline 5. Guanosine & 74 & 76 & - & 122 & 115 & - \\
\hline 6. Guanosine plus methanol & 122 & 58 & 64 & 143 & 85 & 58 \\
\hline 7. 6-mercaptopurine & 109 & 104 & - & 75 & 73 & - \\
\hline 8. 6-MP plus methanol & 131 & 85 & 46 & 96 & 60 & 36 \\
\hline 9. Adenine & 47 & 46 & - & 74 & 75 & - \\
\hline 10. Adenine plus methanol & 72 & 41 & 31 & 99 & 62 & 37 \\
\hline 11. 2,6-diaminopurine & 10 & 10 & - & 15 & 15 & - \\
\hline 12. 2,6-DAP plus methanol & 22 & 10 & 12 & 35 & 15 & 20 \\
\hline 13. Folic acid & 24 & 17 & - & 18 & 12 & - \\
\hline 14. Folic acid plus methanol & 54 & 16 & 38 & 36 & lI & 25 \\
\hline
\end{tabular}

All assays were conducted as described in 'Methods'. The methanol concentration was $10 \%$. The concentration of purine analog was 2.5 $\mathrm{mM}$ except for folic acid which was at $0.1 \mathrm{mM}$. The responses of both the BB and A isozymes were studied. p-nitrophenoxide and phosphate concentrations were measured directly and the methylphosphate was determined by the difference. $p$-NP $=p$-nitrophenoxide, $P_{i}=$ phosphate, Me-P = methyl-phosphate.

${ }^{a} \mu$ Mole product formed $/ 10 \mathrm{~min}$.

a doubling of the transfer to $\mathrm{H}_{2} \mathrm{O}$ and the decrease in methylphosphate formation is only $10 \%$. The net result for both analogs is an enhancement of the rate of reaction relative to reactions with methanol but without analog. By contrast, adenine has a significant negative effect on the rate of methylphosphate production and only minimal enhancing effect on the transfer to $\mathrm{H}_{2} \mathrm{O}$. Thus, the net effect of adenine addition, relative to methanol alone, is a decreased rate of reaction for the BB isozyme. The relative changes are equal for the $\mathrm{AC}$ isozyme with the net effect being zero. In all assays, the addition of modulator changed the product distribution from that observed with methanol alone, reflecting the increased transfer to $\mathrm{H}_{2} \mathrm{O}$ with at least a marginal decrease in the amount of methylphosphate produced. This alteration in product ratio included the several combinations where the overall reaction rate for methanol plus activator was equal to or less than the rate with methanol alone. The amount of phosphate produced never attained the level observed when the assays were conducted with activator but without methanol, but it was always greater than the level produced without activator.

The methanol-enhanced rate observed for assays conducted with folic acid or diaminopurine is ac- counted for by the amount of methylphosphate formed without any increase in the amount of phosphate transfered to $\mathrm{H}_{2} \mathrm{O}$.

\section{Discussion}

The activity of erythrocyte ACP, either in dialyzed hemolystate or as purified preparations, is modulated by purine analogs $(8,9)$. Purine analog modulation of a purified or partially purified low molecular weight tissue enzyme is also observed $(11,20)$. Most data suggest the erythrocyte and tissue $\mathrm{ACP}$ are the same enzyme $(12,18)$ although some differences in properties have been reported (14). The specific mechanism by which an extensive series of purine analogs modulate the activity of this small, monomeric enzyme is not clearly understood. The enhancement of activity via an uncompetitive mechanism $(3,20)$ implies the existence of a second site. Studies of this effect with the low molecular weight tissue $\mathrm{ACP}$, are consistent with a role at the catalytic step involving removal of phosphate from the enzyme (20), which is the rate-limiting step $(21,22)$. The ability of several analogs to modify the enhancing activity of other analogs, without them- 
selves being modulators indicates that the binding of modulator is independent of modulator influence on catalysis. It is also clear that some modulators are maximally active at much lower concentrations than others and when mixed with modulators with lower affinity exert a dominant effect. This suggests that modulators bind with different affinities. The extent of the response to each modulator is genotype specific indicating that the amino acid(s) which differ between the isozymes must be involved, directly or indirectly, with the modulation site (or mechanism). No examples of modulators being inhibitors of one isozyme and an activator of another have been observed.

Enough differences in response to structurally similar analogs are observed to preclude defining absolute requirements for modulation, although several generalizations are possible. It is necessary for the purine base to be substituted at the 6-position for substantial positive modulation. The adduct can be quite large and still be a good activator, e.g. dimethylamino or mercaptoethyl groups, although the chloro adduct is an inhibitor. Adducts at the 2-position, in contrast to similar adducts at the 6-position, tend to be either inactive or inhibitors. The disubstituted analogs are generally intermediate in modulating activity, although all of the 2-amino analogs become inhibitors with the diamino analog being a strong inhibitor. Addition of the ribose moiety confuses the generalization in that the 6-amino substituted analog (adenosine) is no longer an activator while the 2-amino, 6-hydroxyl analog (guanosine) is a strong activator rather than an inhibitor and the phenotype specificity of the 6-hydroxyl analog (inosine) is reversed. Interestingly, addition of a methyl group to either the 1- or 7-nitrogen obliterates the positive modulation capabilities of guanosine.

A bicyclic ring structure appears important as the pyrimidines are generally ineffective as modulators. Increasing the ring size by one carbon atom (pteridine) or creating a pyrazole ring (allopurinol) altered the modulation characteristics for only one of five comparisons.

The analog specificities observed with the erythrocyte enzyme are not inconsistent with the previous results from studies with isozyme III from human placenta (19), although the generally low level of response in the studies of the placental enzyme make significant comparisons difficult. A partially purified human liver low molecular weight ACP have modulation characteristics similar to those observed for the erythrocyte enzyme (11). Significant differences with the results reported for the low molecular weight ACP from bovine brain are evident (20). These include the activation of the brain isozyme by guanine rather than inhibition as observed with the human erythrocyte isozymes. Additionally, the bovine brain isozyme was unresponsive to hypoxanthanine, an activator of the human isozymes. In contrast to the brain enzyme, both the bovine erythrocyte and liver enzyme exhibits responses similar to those observed for the human enzyme (11). It is possible that the differences reflect tissue specificity.

The addition of methanol as a potential phosphate acceptor results in an increased rate of catalysis. Addition of the purine a nalogs (activators), in addition to methanol, has two consequences. The analogs not only increase the amount of phosphate produced relative to no activator or methanol, but also cause a decrease in the a mount of methylphosphate produced relative to methanol alone. Thus the net effect on the total reaction rate reflects the sum of the increased rate of phosphate transfer to $\mathrm{H}_{2} \mathrm{O}$ and the decreased rate of transfer to alcohol. The mechanism for the apparent thresholding, that is, the observation that the modulator must enhance enzyme activity to a level approximately 1.8 times the control activity before it enhances the activity in the presence of $10 \%$ methanol is not immediately evident. Obviously it could involve conformational changes and the relative position of the amino acid residue(s) important for the dephosphorylation (transphosphorylation) step. Under the conditions of these experiments (saturating substrate and modulator, assayed at pH 5.5) it is clear that modulators enhance the transfer of phosphate to $\mathrm{H}_{2} \mathrm{O}$ relative to alcohol. This is observed when the modulator is inhibiting the total reaction rate in the presence of alcohol, or enhancing the reaction rate. Thus the product ratio is a function of the presence of the modulator rather than the rate of the reaction. The data presented here are not inconsistent with the proposal of Tanizaki et al. (20) that purine analogs may change the rate liming step. The modulators could also act by enhancing the ability of $\mathrm{H}_{2} \mathrm{O}$ to act as an acceptor, relative to alcohol, while retaining the rate-limiting step.

The potential physiological significance of the 
purine analog modulation of ACP activity is unclear for several reasons. One would be the apparent non-physiological concentrations of these compounds necessary for significant in vitro modulation. Another would be the lack of a well-defined function for the enzyme, although it is proposed to function as a flavin mononucleotide phosphatase $(8,12)$. Several ACP phenotype-disease associations have been reported including increased susceptibility to hemolytic anemia and jaundice as well as low birth weight and premature birth (26-31). The inverse relationship between the level of erythrocyte ACP activity and glutathione reductase activity (16) suggests a relationship between ACP activity and erythrocyte flavin adenine dinucleotide concentration $(32,33)$ and is consistent with the proposed physiological function of the enzyme.

Further studies of the structural differences among the several variants of this enzyme should provide insight into the mechanisms for the modulation and possibly be useful in studies directed toward further definition of the physiological importance of this enzyme.

\section{Acknowledgement}

This research was supported by a contract from the Department of Energy (EY-77-C-02-2828).

\section{References}

1. Fisher RA, Harris H: Further studies of the molecular size of red cell acid phosphatase. Ann Hum Genet Lond 34: 449-453, 1971.

2. Spencer N, Hopkinson DA, Harris H: Quantitative differences and gene dosage in the human red cell acid phosphatase polymorphism. Nature 20 I:299-300, 1964.

3. Eze LC, Tweedie MCK, Bielben MF, Wren PJJ, Evans DAP: Quantitative genetics of human red cell acid phosphatase. Ann Hum Genet Lond 37:333-340, 1974.

4. Fisher RA, Harris H: Studies on the separate isozymes of red cell acid phosphatase phenotypes $A$ and B. II. Comparison of kinetics and stabilities of the isozymes. Ann Hum Genet Lond 34:439-448, 1971.

5. Yoshihara CM, Mohrenweiser HW: Characterization of $\mathrm{ACP}_{1}{ }^{\text {TIC-I }}$, an electrophoretic variant of erythrocyte acid phosphatase restricted to the Ticuna Indians of Central Amazonas. Am J Hum Genet 32:898-907, 1980.

6. Mohrenweiser $\mathrm{HW}$, Novotny JE: $\mathrm{ACP}_{1} \mathrm{GUA}^{-1}-\mathrm{A}$ low-activity variant of human erythrocyte acid phosphatase: Association with increased glutathione reductase activity. Am J Hum Genet 34:425-433, 1982.
7. Luffman JE, Harris H: A comparison of some properties of human red cell acid phosphatase in different phenotypes. Ann Hum Genet 30:387-401, 1967.

8. Mansfield ${ }^{\circ}$, Sensabaugh GF: Red cell acid phosphatase: modulation of activity by purines. In: Brewer GJ (ed), The Red Cell, Vol 4. Alan R Liss, Inc, New York, 1978, pp 233-247.

9. Mansfield E, Sensabaugh GF: Phenotypic differences in purine modulation of erythrocyte acid phosphatase activity. Lancet 2:201-202, 1977

10. Sensabaugh GF, Golden VL: Phenotype dependence in the inhibition of red cell acid phosphatase (ACP) by folates. Am J Hum Genet 30:553-560, 1978.

11. Naidu JM, Mohrenweiser HW: Erythrocyte acid phosphate: Species specificity in activity modulation by purine analogs. Comp Biochem Phys (in press).

12. Sensabaugh GF: Genetic and nongenetic variation of human acid phosphatases. In: Markert CL(ed), Isozymes I: Molecular Structure. Academic Press, New York, 1975, pp 367-380.

13. Lawrence GL, VanEtten RL: The low-molecular-weight acid phosphatase from bovine liver: isolation, a mino acid composition, and chemical modification studies. Arch Biochem Biophys 206:122-131, 1981.

14. Taga EM, VanEtten RL: Human liver acid phosphatase: purification and properties of a low-molecular-weight isoenzyme. Arch Biochem Biophys 214:505-515. 1982.

15. Rehkop DM, VanEtten, RL: Human liver acid phosphatases. Hoppe-Zeiler's Z Physiol Chem 356:1775-1782, 1975.

16. Saini MS, VanEtten RL: A homogeneous isozyme of human liver acid phosphatase. Arch Biochem Biophys 191:613-624, 1978.

17. Chaimovich H, Nome F: Purification and properties of acid phosphatase from bovine brain. Arch Biochem Biophys 139:9-16, 1970.

18. Swallow DM, Povey S, Harris H: Activity of the 'red cell' acid phosphatase locus in other tissues. Ann Hum Genet Lond 37:31-38, 1973.

19. DiPietro DL, Zengerle FS: Separation and properties of three acid phosphatases from human placenta. J Biol Chem 243:3391-3396, 1967 .

20. Tanizaki MA, Bittencourt HMS, Chaimovich H: Activation of low molecular weight acid phosphatase from bovine brain by purines and glycerol. Biochim Biophys Acta 485:116-123, 1977.

21. Baldijao CEM, Guija E, Bittencourt HMS, Chaimovich H: Steady state kinetics and the effect of $\mathrm{SH}$ inhibitors on acid phosphatase from bovine brain. Biochim Biophys Acta 391:316-325, 1925.

22. Saini MS, Buchwald SL, VanEtten RL, Knowles JR: Stereochemistry of phospho transfer catalyzed by bovine liver acid phosphatase. Proc Natl Acad Sci USA 256: 10453-10455, 1981.

23. Fielek S, Mohrenweiser HW: Erythrocyte enzyme deficiencies assessed with a miniature centrifugal analyzer. Clin Chem 25:384-388, 1979.

24. Neel JV, Mohrenweiser HW, Meisler MM: Rate of spontaneous mutation at human loci encoding protein structure. Proc Natl Acid Sci USA 77:6037-6041, 1980.

25. Lanzetta PA, Alvarez LJ, Fieinach PS, Candia CA: An improved assay for nanomole amounts of inorganic phosphate. Anal Biochem 100:95-97, 1979. 
26. Valentine WN, Tanaka RR, Fredricks RE: Erythrocyte acid phosphatase in health and disease. Am J Clin Pathol 36:328-332, 1961.

27. Bottini E, Lucarelli P, Bastianon V, Gloria F: Erythrocyte acid phosphatase polymorphism and haemolysis. J Med Genet 9:434-435, 1972.

28. Bottini E, Scacchi R, Gloria-Bottini F, Mortera J, Palmarino R, Carapella-deLuca E, Lapi AS, Noclari D: Neonatal jaundice and erythrocyte acid phosphatase phenotype. Lancet 1:918, 1976.

29. Carapella E, Pascone R, Gori MG, Matteucci P, Gloria-Bottini F, Morthera J, Lucarelli P, Scacchi R, Bottini E: The genetic component of quantitative perinatal variables. An analyses of relations between erythrocyte acid phosphatase phenotype and birth weight, gestational age and serum bilirubin level in the first days of life. J Perinat Med 8:42-47, 1980.
30. Bottini E, Lucarelli P, Agostino R, Palmarino R, Businco L, Antognori G: Favism: association with erythrocyte acid phosphatase phenotype. Science 171:409, 1971.

31. Bottini E, Carapella E, Orzalesi M, Lucarelli P, Pascone R, Gloria-Bottini F, Coccia M: Is there a role of erythrocyte acid phosphatase polymorphis $m$ in intrauterine development. Am J Hum Genet 32:764-767, 1980.

32. Nichoalds GE, Lawrence JD, Sauberlich HE: Assessment of status of riboflavin nutriture by assay of erythrocyte glutathione reductase activity. Clin Chem 20:624-628, 1974.

33. Brewster MA, Berry DH, Murphey MN: Automated reaction rate analysis of erythrocyte glucose 6-phosphate dehydrogenase and glutathione reductase activities. Biochem Med 10:229-235, 1974.

Received in revised form 2 November 1984. 